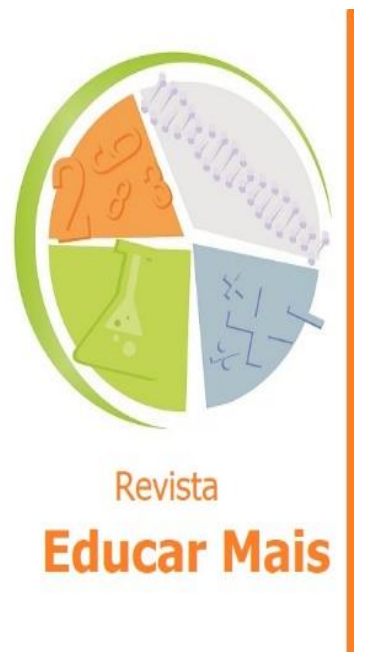

\section{Estudo de teses e dissertações nacionais sobre Feiras de Ciências: mapeamento dos elementos que envolvem uma Feira de Ciências e suas interligações}

\author{
Study of national thesis and dissertations on Science Fairs: mapping \\ the elements that involve a Science Fair and its interconnections
}

Estudio de tesis nacional $\boldsymbol{y}$ disertaciones sobre Ferias de Ciencia: mapeo de los elementos que involucran una feria de Ciencia $y$ sus interconexiones

Cicero Gularte Scaglioni ${ }^{1}$; Bruna Andrieli Ilha Pereira ${ }^{1}$; Tobias de Medeiros Rodrigues"; Ivo Leite Filho ${ }^{2}$; Pedro Fernando Teixeira Dorneles ${ }^{1}$

\begin{abstract}
RESUMO
Atualmente ocorrem dezenas de Feiras de Ciências em nosso país. Diante disso, buscamos realizar um levantamento para catalogarmos, em uma planilha eletrônica, os trabalhos de pós-graduação em stricto sensu desenvolvidos no Brasil sobre Feiras de Ciências. Foram localizadas 111 dissertações e 13 teses, tendo como trabalho pioneiro a dissertação de Ronaldo Mancuso de 1993. Tal levantamento demonstrou uma tendência de crescimento no número de trabalhos ao longo dos últimos anos, pois das 124 produções analisadas 109 são do período de 2010 a 2019. Destacamos como possível indício o fomento das chamadas anuais do CNPq de apoio a Feiras e Mostras Científicas. Em relação ao processo de categorização final, encontramos uma dispersão no foco dos trabalhos, pois muitos, apesar de citarem Feira de Ciências, não a tiveram como tema central de pesquisa. Foi identificado que o termo "Feira de Ciências" muitas vezes é usado sem definição consensual. Assim, realizamos uma síntese sobre as definições de Feiras de Ciências apresentadas em publicações de autores renomados no tema. Essa síntese propiciou uma construção de 10 objetivos e a elaboração do mapa de elementos que envolvem uma Feira de Ciências e suas interligações.
\end{abstract}

Palavras-chave: Feiras de Ciências; Pós-Graduação; Levantamento Bibliográfico.

\begin{abstract}
There are currently dozens of Science Fairs in our country. Therefore, we seek to carry out a survey to catalog, in an electronic spreadsheet, the postgraduate work in stricto sensu developed in Brazil on Science Fairs. We found 111 dissertations and 13 theses, with the pioneering work of Ronaldo Mancuso's 1993 dissertation. This survey showed a growth trend in the number of works over the past few years, since 109 of the 124 productions analyzed are from the period 2010 to 2019. We highlight as a possible indication the promotion of CNPq's annual calls to support Science Fairs and Exhibitions. Regarding the final categorization process, we found a dispersion in the focus of the works, since many, despite citing Science Fair, did not have it as a central research theme. It was identified that the term "Science Fair" is often used without a consensus definition. Thus, we carried out a synthesis on the definitions of Science Fairs presented in publications of renowned authors on the theme. This synthesis enabled the construction of 10 objectives and the elaboration of the map of elements that involve a Science Fair and its interconnections.
\end{abstract}

Keywords: Science Fairs; Postgraduate studies; Bibliographic survey.

\footnotetext{
${ }^{1}$ UNIPAMPA - Universidade Federal do Pampa, Bagé/RS - Brasil.

2 UFMS - Universidade Federal de Mato Grosso do Sul, Campo Grande/MS - Brasil.
} 


\section{RESUMEN}

Actualmente existen decenas de Ferias de Ciencias en nuestro país. Por lo tanto, buscamos realizar una encuesta para catalogar, en una hoja de cálculo electrónica, el trabajo de posgrado en stricto sensu desarrollado en Brasil sobre Ferias de Ciencias. Se encontraron 111 disertaciones y 13 tesis, siendo pionero el trabajo pionero de la disertación de Ronaldo Mancuso 1993. Esta encuesta mostró una tendencia de crecimiento en el número de trabajos en los últimos años, ya que de las 124 producciones analizadas 109 son del período 2010 a 2019. Destacamos como posible indicio la promoción de las convocatorias anuales del CNPq para apoyar Ferias y Exposiciones Científicas. En cuanto al proceso de categorización final, encontramos una dispersión en el enfoque de los trabajos, ya que muchos, a pesar de citar la Feria de Ciencias, no lo tenían como tema central de investigación. Se identificó que el término "Feria de Ciencias" se usa a menudo sin una definición de consenso. Así, realizamos una síntesis sobre las definiciones de Ferias de Ciencias presentadas en publicaciones de reconocidos autores sobre el tema. Esta síntesis permitió la construcción de 10 objetivos y la elaboración del mapa de elementos que involucran una Feria de Ciencias y sus interconexiones.

Palabras clave: Ferias de ciencia; Posgraduación; Encuesta bibliográfica.

\section{INTRODUÇÃO}

Desde a década de 1960, as Feiras de Ciências no Brasil passaram por consideráveis transformações trazendo o protagonismo do estudante, o foco no interesse do que realmente desejam investigar e o papel social das pesquisas. Dessa forma, o professor orientador de trabalhos para Feiras de Ciências passou a assumir um papel de mediador e facilitador na busca do conhecimento e, assim, as feiras podem se tornar um ambiente potencial para pesquisas em Ensino. Porém, atualmente as publicações acadêmicas sobre Feiras de Ciências não refletem as dezenas de feiras que ocorrem anualmente em nosso país.

Na literatura nacional, destaca-se o trabalho pioneiro de Gallon et al. (2017) sobre um levantamento de trabalhos sobre Feiras de Ciências nas edições do Encontro Nacional de Pesquisa em Educação em Ciências (ENPEC) no período de 1997 a 2015: foram encontrados apenas 24. Em outro trabalho de revisão da literatura (PEREIRA, 2019) foram encontrados apenas seis artigos em cinco revistas de ensino, sendo elas: Revista Brasileira de Ensino de Ciência e Tecnologia, Investigações em Ensino de Ciências, Experiências em Ensino de Ciências, Revista Brasileira de Pesquisa em Educação em Ciências e Ciência \& Educação.

No presente trabalho, buscamos, então, ampliar as buscas de trabalhos sobre Feiras de Ciências com base nas produções nacionais de dissertações e teses disponíveis no Catálogo de Teses e Dissertações da Capes (BTC), na Biblioteca Digital Brasileira de Teses e Dissertações (BDTD) e no Portal Brasileiro de Publicações Científicas em Acesso Aberto (OASISBR). Com tal levantamento, tivemos os objetivos de:

i) apontar o tipo de titulação (Mestrado ou Doutorado);

ii) identificar a distribuição dos trabalhos por regiões do Brasil;

iii) analisar o número de trabalhos por ano;

iv) criar categorias sobre o foco das produções encontradas e

v) analisar a ocorrência dos objetivos esperados em uma Feira de Ciência (discutidos e fundamentados na próxima seção). 


\section{FEIRA DE CIÊNCIAS E SEUS OBJETIVOS}

Ao analisarmos as publicações encontradas, percebemos que o termo "Feira de Ciências" é usado sem uma definição consensual. Assim, surgiram indagações iniciais: "O que está sendo denominado de Feiras de Ciências é realmente uma Feira de Ciências?" e "As Feiras de Ciências realizadas atualmente estão em sintonia com os objetivos esperados de uma Feira?". Procuramos na literatura as definições mais utilizadas, sobre as quais passamos a discorrer.

Em uma publicação do Centro de Ciências do Rio Grande do Sul (CECIRS), encontramos a seguinte definição para Feiras de Ciências:

É uma atividade cultural realizada por estudantes, no sentido de proporcionar, por meio de demonstrações por eles planejadas e executadas, uma amostra do seu trabalho, do seu conhecimento e das realizações humanas no campo técnicocientífico. Constitui-se, ainda, no melhor momento e na melhor forma de atuação da escola na comunidade, pela oportunidade de levar e gerar desenvolvimento cultural. (CECIRS, 1970, p. 2).

Em uma publicação da década de 80 , Moraes (1986, p. 20) também destaca a relação entre escola e comunidade: "A Feira de Ciências é um empreendimento técnico-científico-cultural que se destina a estabelecer o inter-relacionamento entre a escola e a comunidade". Ele, ainda, apresenta o diferencial de os alunos usarem a criatividade, o raciocínio lógico, a capacidade de pesquisa e conhecimentos científicos para planejar e executar projetos.

Além disso, a oportunidade de interação com o público para o compartilhamento de conhecimento é destacada por SECAB/UNESCO (1985) e Ormastroni (1990). Para SECAB/UNESCO (1985, p. 10), uma Feira de Ciências se caracteriza pela:

Exposição pública de trabalhos científicos realizados por jovens, na qual estes oferecem explicações, respondem perguntas sobre seus métodos e conclusões, e uma comissão seleciona os trabalhos de acordo com os conhecimentos, originalidade, pensamento científico e habilidade na apresentação.

Ormastroni (1990, p. 7) destaca a possibilidade de troca de conhecimento, mas também levanta a viabilidade de "contestação de perguntas sobre os métodos e suas condições".

De forma semelhante, Mancuso (2006 apud MANCUSO; LEITE FILHO, 2006, p. 20) destaca o diálogo com os visitantes e aponta a possibilidade de as feiras ocorrerem nas comunidades e envolverem eventos sociais e culturais:

Feiras de Ciências são eventos sociais, científicos e culturais realizados nas escolas ou na comunidade com a intenção de, durante a apresentação dos estudantes, oportunizar um diálogo com os visitantes, constituindo-se na oportunidade de discussão sobre os conhecimentos, metodologias de pesquisa e criatividade dos alunos em todos os aspectos referentes à exibição dos trabalhos.

Destacamos que tais definições já foram tratadas por Mancuso e Leite Filho (2006, p.20), os quais concluíram, principalmente que:

[...] Os trabalhos apresentados nas feiras (ou mostras ou exposições, qualquer que seja a denominação) deverão ser realizados pelos alunos, mediados por um ou mais professores, sob a tutela da escola (intra ou extra classe) e voltados para a comunidade que gravita em torno dela. 
Embora numa feira apareçam trabalhos de muitos tipos (o que será apresentado adiante), atualmente a ênfase maior passou a ser de cunho social em que os alunos levantam a problemática e, sempre que possível, buscam soluções para as dificuldades mais prementes da comunidade, evidenciando o caráter político da educação.

Por último, citamos uma publicação mais recente e internacional. Trata-se do livro intitulado Science Education and Citizenship: Fairs, Clubs, and Talent Searches for American Youth, 1918-1958 (Educação Científica e Cidadania: Feiras, Clubes e Pesquisas de Talentos para Jovens Americanos, 1918-1958), em que Terzian (2013) destaca o potencial das feiras de: expor os alunos a novas ideias sobre o mundo natural, mobilizá-los para aprender a resolver problemas de interesse mútuo, aumentarem sua consciência social e provocar seu envolvimento com assuntos da comunidade.

Em relação aos objetivos de uma Feira de Ciências, baseamo-nos principalmente no primeiro capítulo da obra de Terzian (2013), que trata das origens dos Clubes e Feiras de Ciências, baseado na trajetória de Morris Meister (professor de ciências em escolas de Nova York na década de 1920 e pioneiro em incentivar a realização de Feiras de Ciências para crianças). Dessa forma, sintetizamos dez objetivos das Feiras de Ciências:

1) Envolver os alunos em experimentos práticos no Ensino de Ciências em sala de aula, em clubes de ciências, em turno inverso e em espaços não formais de ensino;

2) Utilizar o contexto social dos estudantes para promover o inter-relacionamento entre a escola e a comunidade;

3) Tornar a ciência mais significativa e influente na vida dos jovens;

4) Promover sentimentos de pertencimento dos alunos apresentadores de trabalhos;

5) Despertar em alunos da Educação Básica, independentemente de se tornarem cientistas, o interesse e a valorização do conhecimento científico em suas atividades cotidianas;

6) Instigar a curiosidade dos alunos sobre a ciência enquanto se fomentam investigações autorais sobre problemas de interesse mútuo;

7) Desenvolver a aprendizagem ativa, atividades interdisciplinares e experiências individualmente significativas;

8) Fomentar a argumentação, o interesse pela cidadania saudável e o progresso social;

9) Promover a alfabetização científica;

10) Despertar a criticidade nos métodos e resultados.

A título de síntese, construímos um mapa de elementos que envolvem Feiras de Ciências e suas interligações (Figura 1), tendo Feira de Ciências ao centro e os professores, estudantes, Ciências, senso comum, espaços não formais de ensino, comunidades, escolas, universidades e projetos como os principais elementos (realce em amarelo). Destacamos que feiras envolvem especialmente: Ensino de Ciências, iniciação científica, sala de aula, turno inverso, espaços não formais de ensino, Clubes de Ciências, inovação e tecnologia, contexto social, experimentação e atividades interdisciplinares. Em relação aos estudantes, elas propiciam principalmente: aprendizagem ativa, alfabetização científica, progresso social, argumentação, interesse pela cidadania saudável, sentimentos de pertencimento, curiosidade e criticidade. Aos professores, proporcionam formação continuada, divulgação científica e um ensino contextualizado. Com destaque para a espessura das linhas dos 
conectores, demos ênfase ao relacionamento entre Ciências, escolas, universidades, comunidades e estudantes. No mapa também se realça a importância das feiras em despertar o interesse pela ciência, o que pode torná-la mais significativa e presente na vida dos estudantes. Sobre os projetos de trabalhos desenvolvidos e apresentados em feiras, evidencia-se a característica de serem trabalhos de interesse dos estudantes.

Os conceitos de projetos, estudantes e professores foram interligados, pois os projetos frequentemente são concebidos segundo bases teóricas, epistemológicas e metodológicas dos professores, justificando a importância da presença do conceito de formação continuada para se ultrapassar a proposição de projetos que simplesmente apresentam uma demonstração experimental, ou seja, é uma formação que visa propiciar a adoção e o questionamento de procedimentos de Ciências, levando em conta o contexto social dos estudantes para a produção de conhecimento.

Por fim, cabe salientar que este mapa é uma primeira tentativa de representação conceitual das Feiras de Ciências. Assim, trabalhos futuros poderão apresentar a incorporação e/ou retirada de elementos e relações, pois o tema é amplo e, em casos mais específicos, particularidades podem requerer alterações. A seguir passamos a apresentar a metodologia adotada e destacamos que as publicações encontradas serão utilizadas para complementarmos a sintetização do conceito de Feiras de Ciências

Figura 1 - Mapa dos elementos que envolvem uma Feira de Ciências e suas interligações.

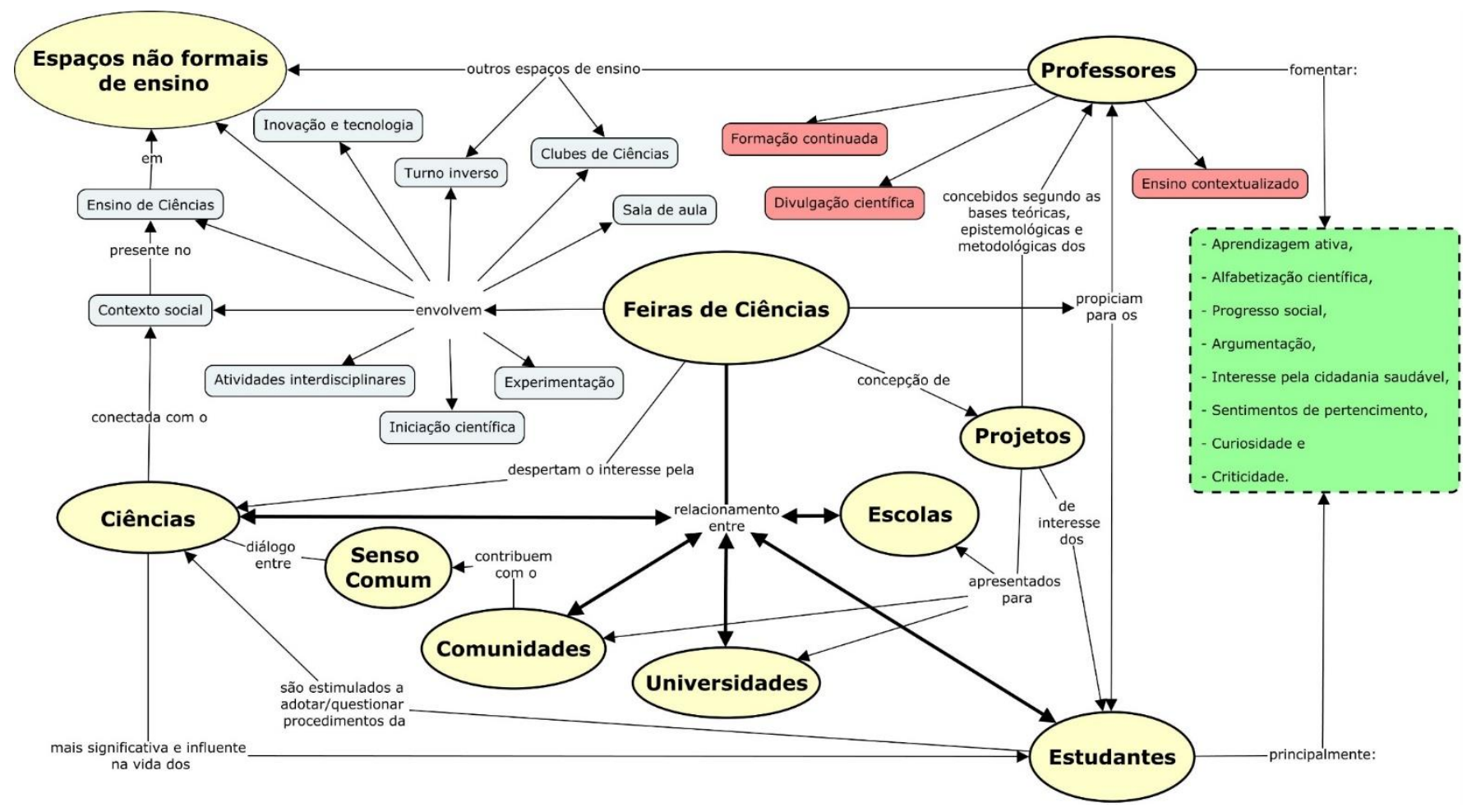

Fonte: Autores, 2020.

\section{METODOLOGIA}

Realizamos esta pesquisa para investigar o que vem sendo produzido sobre Feiras de Ciências nos programas de Pós-Graduação stricto sensu do Brasil. Ao pesquisarmos no BTC, BDTD e OASISBR, identificamos divergências nos números de publicações. Assim, optamos por realizar buscas individuais em cada portal e posteriormente compilamos todos os dados encontrados. Para realizar 
as buscas, utilizamos o sistema de busca avançada e as seguintes combinações: "Feiras de Ciências" OR "feiras de ciências" OR "Feiras de ciências" OR "feiras de Ciências" OR "Feira de Ciências" OR "feira de ciências" OR "Feira de ciências" OR "feira de Ciências".

Conforme ilustrado na Figura 2, os números dos portais diferiram significativamente. Do universo de 211 trabalhos identificados, encontramos 124 sem repetições e somente 35 trabalhos se repetem nos três portais, justificando assim a necessidade de pesquisas em mais de um portal.

Figura 2 - Diagrama do número de trabalhos encontrados por fonte consultada e suas respectivas intersecções.

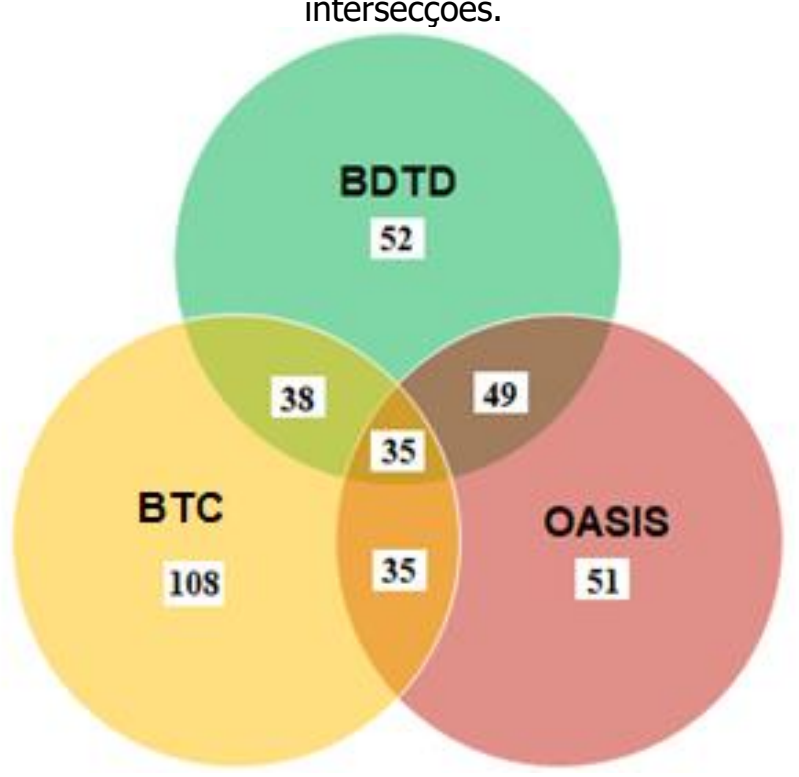

Fonte: Os autores, 2020.

Ao selecionarmos todos os trabalhos que continham no mínimo uma referência sobre Feira de Ciências, excluímos trabalhos desenvolvidos em escolas e programas de pós-graduação fora do Brasil (duas produções de Portugal) e trabalhos que apenas citavam que uma atividade cultural foi apresentada durante a abertura de uma feira. Porém, destacamos que, dos 124 trabalhos selecionados, não necessariamente todos tiveram o foco em Feiras de Ciências. A opção por não realizar inicialmente uma seleção focada nos objetivos traçados no item anterior se deu pelo fato de termos como objetivo a construção de uma planilha eletrônica com o máximo de informações possível e que possibilite aos leitores a realização de filtros para encontrar informações mais específicas.

A planilha com dados de publicações até $2019^{3}$ contém: os títulos dos trabalhos (com hiperlinks para acesso integral às produções), autores, orientadores, ano, instituição de ensino, categorização sobre o foco das produções, classificação sobre os objetivos conceituais de uma feira, etc.

Em relação à categorização sobre o foco das produções, foram analisados os títulos e os resumos e nos baseamos no trabalho de Gallon (2017) para, a priori, termos três categorias iniciais: Categoria I - Produções sobre Feiras de Ciências centradas nos eventos; Categoria II - Produções sobre Feiras de Ciências centradas nos estudantes e Categoria III - Produções sobre Feiras de Ciências centradas nos professores. Ao longo das análises, identificamos a necessidade de criar mais duas categorias: Categoria IV - Produções com outros objetivos que propiciaram a apresentação de trabalhos e/ou a

\footnotetext{
${ }^{3}$ Disponível em: https://drive.google.com/drive/folders/1II00KwYo4PJ_-IBgqOkUfdw36EDBBrVM?usp=sharing. Acesso em 29 de outubro de 2020.
} 
realização de Feiras de Ciências e Categoria V - Produções que envolvem Feiras de Ciências como uma atividade relacionada ao tema pesquisado.

Sobre a ocorrência dos objetivos esperados em uma Feira de Ciência, focamos nos títulos, nas palavras-chave e nos resumos. Encontramos três grupos de classificação: Grupo A - Apresentação de referência direta aos termos Feiras de Ciências e/ou Mostra Científica e também apontam um ou mais objetivos das Feiras de Ciências; Grupo B - Sem apresentação de referência direta aos termos Feiras de Ciências e/ou Mostra Científica, mas apontam um ou mais objetivos das Feiras de Ciências; Grupo C - Sem a apresentação de objetivos das Feiras de Ciências.

\section{RESULTADOS}

\subsection{Descrição quantitativa}

As 124 teses e dissertações encontradas estão agrupadas por regiões no Apêndice A. São predominantemente dissertações (58 de Mestrados Profissionais e 53 de Acadêmicos); apenas 13 são Teses de Doutorado.

Em vista da dimensão territorial brasileira, conforme a Figura 3, encontramos apenas três estados com mais de 10 trabalhos (São Paulo, Rio Grande do Sul e Minas Gerais).

Figura 3 - Distribuição por regiões e estados do Brasil do número de teses e dissertações.

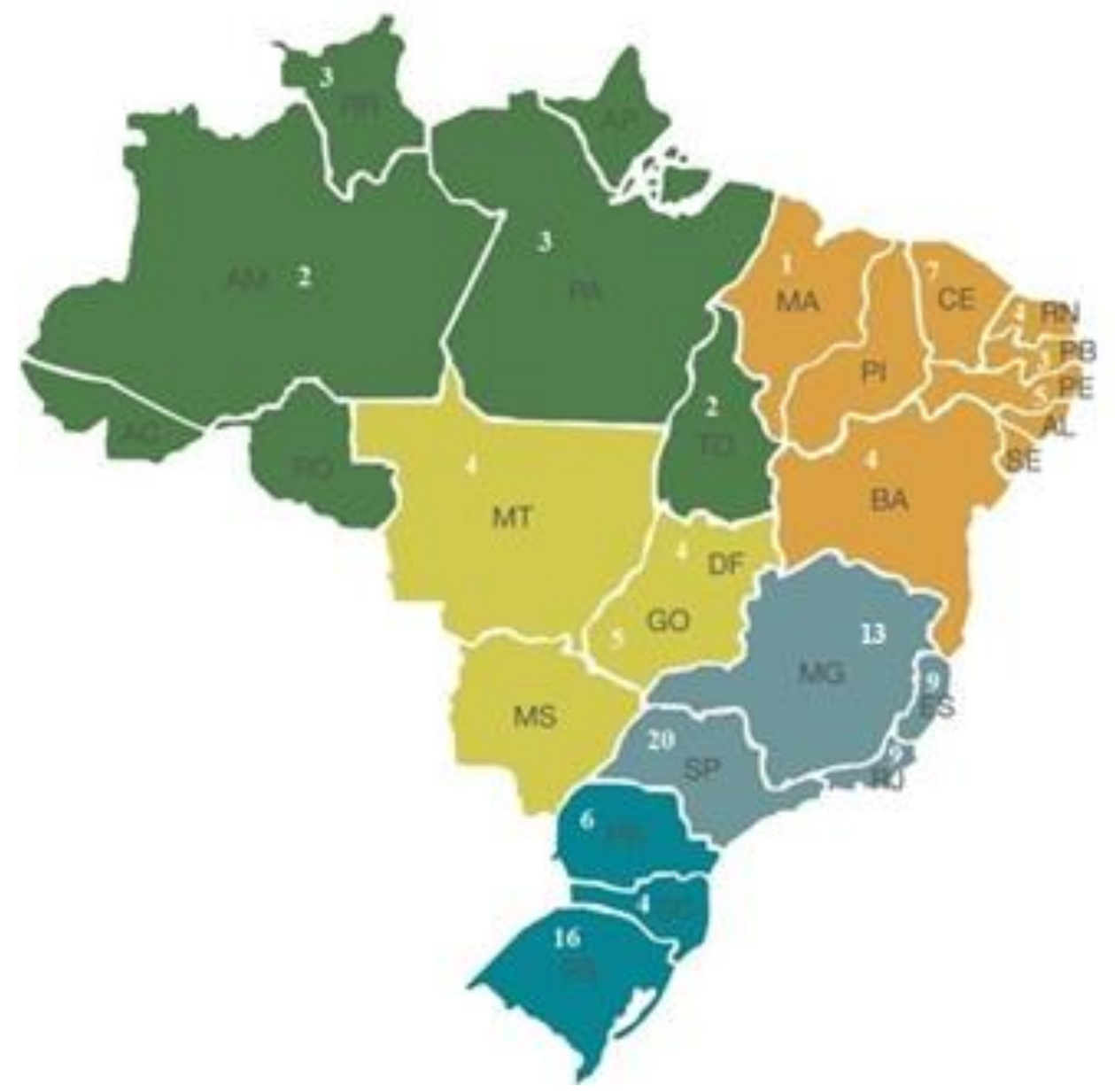

Fonte: Os autores, 2020. 
Ao analisarmos a distribuição dos trabalhos por ano de publicação, encontramos que ao longo dos anos tem tido uma tendência de aumento. No entanto, essa tendência não é constante, isto é, em determinados momentos ocorrem aumentos significativos e em seguida há uma tendência momentânea de queda (Figura 4). Este resultado mostra que, a partir de 2012, as variações negativas passaram a ser menores que as positivas, evidenciando um aumento significativo no número de trabalhos. Tal crescimento pode estar relacionado com as constantes chamadas de financiamento do CNPq e com o aumento dos programas de pós-graduação no Brasil.

Figura 4 - Gráfico do número de trabalhos por ano de publicação

25

20

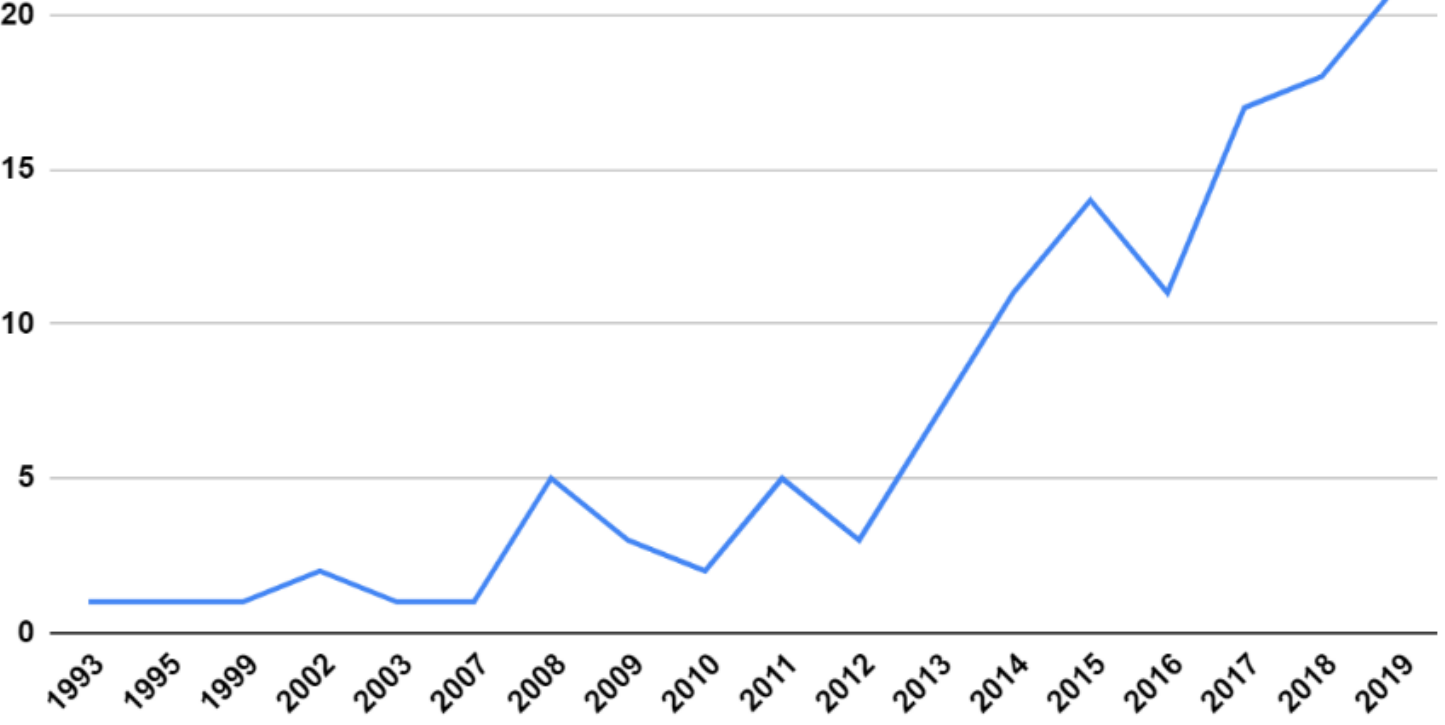

Fonte: Os autores, 2020.

\subsection{Análise sobre o foco das produções encontradas}

Ao analisarmos os títulos e resumos dos trabalhos encontrados, identificamos que muitos não tiveram Feiras de Ciências como objetivo principal, mas que, em seu decorrer, surgiu uma relação com o tema Feira de Ciências. Esses trabalhos foram classificados na Categoria V (30 trabalhos). Em outros 33 trabalhos, encontramos narrativas que não têm feiras como foco, mas eles foram realizados e apresentados em uma feira (Categoria IV). Dos demais 61, 59 foram classificados segundo a proposta de Gallon et al. (2017), sendo 40 na Categoria I (Produções sobre Feiras de Ciências centradas nos eventos), 10 na Categoria II (Produções sobre Feiras de Ciências centradas nos estudantes) e nove na Categoria III (Produções sobre Feiras de Ciências centradas nos professores). Dois trabalhos não foram categorizados porque seus resumos não estavam disponíveis para consulta na forma digital. Assim, observamos que menos da metade dos trabalhos teve como foco principal uma investigação sobre Feiras de ciências. Porém, destacamos que os trabalhos das categorias IV e V são produções que apresentam elementos e resultados que podem subsidiar tanto a realização de novas feiras quanto novas pesquisas.

No Quadro 1 apresentamos, a título de ilustração, dois trabalhos por categoria, contendo autor, título e recortes do resumo. 
Quadro 1 - Ilustração dos trabalhos por categoria

\begin{tabular}{|l|}
\hline \multicolumn{1}{|c|}{ Categoria, Autor, Ano e Título } \\
\hline Categoria I - Vitor (2016). \\
AS FEIRAS DE CIÊNCIAS COMO AMBIENTE \\
PARA A ALFABETIZAÇÃO CIENTÍFICA \\
\\
\hline Categoria I - Nascimento Filho (2014). UM \\
OLHAR SOBRE AS 1a E 2a FEIRAS DE \\
CIÊNCIAS E ENGENHARIA DO ESPÍRITO \\
SANTO: A PEDAGOGIA DE PROJETOS A \\
SERVIÇO DA EDUCAÇÃO CIENTÍFICA
\end{tabular}

Categoria II - Depieri (2014). A ENGENHARIA SOB A OTICA DOS PRÉUNIVERSITÁRIOS E O IMPACTO DAS FEIRAS DE CIÊNCIAS

Categoria II - Matos (2014). MOSTRA DE CIÊNCIAS E TECNOLOGIA: INSTRUMENTO DE MUDANÇA NA VISÃO DOS CALOUROS SOBRE A FUNÇÃO DA ENGENHARIA NO MUNDO MODERNO

Categoria III - Santos (2019). FEIRAS DE CIÊNCIAS NO ENSINO MÉDIO: ATUAÇÃO DOS PROFESSORES NO CONTEXTO DA PRÁTICA

Categoria III - Duarte (2009). PROFESSORES DAS SÉRIES INICIAIS DO ENSINO FUNDAMENTAL E AS FEIRAS DE CIÊNCIAS

Categoria IV - Soares (2015). APRENDIZAGEM SIGNIFICATIVA ATRAVÉS DA CONSTRUÇÃO DE EXPERIMENTOS PELOS ALUNOS DO ENSINO MÉDIO TÉCNICO

Categoria IV - Caldas (2017). ATIVIDADES EXPERIMENTAIS DE ACÚSTICA PARA O ENSINO DE FÍSICA: UMA PROPOSTA NA INCLUSÃO DE SURDOS.
Transcrições de parte dos resumos

Assim, neste trabalho apresentamos uma proposta de Alfabetização Científica a ser realizada através das Feiras de Ciências ... Como base para a elaboração da Feira, considerouse os conhecimentos da comunidade escolar, introduzindo o tema Ambientes Recifais, no qual a escola está inserida.

O objetivo desta pesquisa foi analisar a contribuição das $1^{a}$ e $2^{a}$ Feiras Estaduais de Ciência e Engenharia do ES (FECEES), a partir da Pedagogia de Projetos, para o ensino de ciências.

Estudantes envolvidos com o desenvolvimento de projetos investigativos e participação em feiras de ciências revelaram atitudes mais positivas e mais autoconfiança do que os não envolvidos

Nosso objetivo foi realizar e avaliar como a participação em uma mostra de Ciências pode ser um recurso pedagógico produtor de conhecimento, um instrumento motivacional e que também contribui para que os alunos trabalhem melhor em equipe.

Em nosso trabalho analisamos como os docentes atuam a política de Iniciação científica de alunos do ensino médio voltada para as Feiras de Ciências.

O presente estudo tem como objetivo levantar os saberes utilizados e quais critérios orientaram oito professores participantes da pesquisa para a realização de uma Feira de Ciências nas séries iniciais do Ensino Fundamental em uma escola pública estadual na região metropolitana de São Paulo.

Este trabalho relata a busca de evidências de aprendizagem significativa através da proposta de construção de experimentos que foram construídos pelos alunos e apresentado numa feira de ciências.

Neste trabalho apresentamos a importância da utilização dos experimentos nas aulas de física como um instrumento do ensino aprendizagem para uma abordagem à inclusão de surdos, visando-o como um facilitador para o ensino de conceitos sobre acústica ... ... bem como o desenvolvimento de uma Feira de Ciências na referida escola.

A criação do imaginário científico da criança e do jovem é muito influenciada pelo discurso do professor em sala de aula, principalmente pela forma como este relata, aborda e discute temas ligados à CT\&I, pelo material didático utilizado e pelo valor que dá às atividades fora da sala de aula, como visitas a museus, jardins botânicos e feiras de ciências, entre outras atividades. 
Categoria V - Silva (2013). AÇÕES DE EDUCAÇÃO ALIMENTAR E NUTRICIONAL NO ÂMBITO DO PROGRAMA NACIONAL DE ALIMENTAÇÃO ESCOLAR EM MUNICÍPIOS GOIANOS
Em 195 (90,3\%) municípios, os entrevistados afirmaram que as ações de educação alimentar e nutricional são realizadas, sendo mais frequentes palestras (81,7\%), atividades lúdicas $(54,3 \%)$ e eventos, como a Semana da Alimentação e a Feira de Ciências $(32,6 \%)$.

Fonte: Os autores, 2020.

Em relação a tal categorização cabe destacar que por se tratar de trabalhos de mestrado e doutorado (trabalhos extensos), em alguns casos, nas categorias I, II e III encontramos certa dificuldade para definir qual categoria mais adequada, pois alguns trabalhos tiveram tanto foco nos estudantes quanto nos professores. Além disso, trabalhos com objetivo na análise de uma feira, mas com resultados predominantes sobre estudantes ou professores. Diante de tais questões, optamos por adotar a categoria com maior predominância nos objetivos e nos resultados descritos nos resumos, mas salientamos que para pesquisas com objetivos mais específicos recomendamos a análise integral do documento e a criação de subcategorias, por exemplo na categoria com foco nos eventos podem emergir subcategorias como: avaliação de etapas anteriores a realização da feira, avaliação dos processos de avaliação dos trabalhos, histórico de feiras, avaliação da temáticas dos trabalhos e etc.

\subsection{Análise sobre a ocorrência dos objetivos esperados em uma Feira de Ciências}

Baseados nos objetivos e no mapa de elementos que envolvem uma Feira de Ciências e suas interligações (Figura 1), apresentados na segunda seção, classificamos:

- 52 trabalhos no Grupo A (Apresentação de referência direta aos termos Feiras de Ciências e/ou Mostra Científica) e apontam um ou mais objetivos das Feiras de Ciências;

- 39 no Grupo B (Sem apresentação de referência direta aos termos Feiras de Ciências e/ou Mostra Científica), mas apontam um ou mais objetivos das Feiras de Ciências e;

- 31 no Grupo C (Sem a apresentação de objetivos das Feiras de Ciências).

A título de exemplo, são apresentados no Quadro 2, dois trabalhos por grupos. Nos grupos A e B grifamos em negrito as referências sobre Feiras de Ciências e os indícios dos objetivos elencados no final da Seção 2.

Quadro 2 - Ilustração sobre a categorização dos grupos

Grupo, Autor, Ano e Título (grifo nosso)

Grupo A - Sousa (2015). AS FEIRAS DE CIÊNCIAS EM RORAIMA NO PERÍODO DE 1986 A 2008: CONTRIBUIÇÃO PARA A INICIAÇÃO À EDUCAÇÃO CIENTÍFICA

Grupo A - Lima (2019). FEIRA DE CIÊNCIAS: INTERDISCIPLINARIDADE NO ENSINO DE BIOLOGIA PARA O ENSINO MÉDIO

Grupo B - Godinho (2008). A INICIAÇÃO À EDUCAÇÃO CIENTÍFICA COMO FERRAMENTA PARA A FORMAÇÃO DO JOVEM PESQUISADOR: CONHECENDO AS POTENCIALIDADES PROCEDIMENTAIS E ATITUDINAIS A SEREM DESENVOLVIDAS NOS CAMINHOS INVESTIGATIVOS

Grupo B - Rodrigues (2016). A INICIAÇÃO CIENTÍFICA JÚNIOR MULTIDISCIPLINAR COMO FACILITADORA DA ALFABETIZAÇÃO CIENTÍFICA 
Grupo C - Melo (2013). AÇÕES COLABORATIVAS EM CONTEXTO ESCOLAR: DESAFIOS E POSSIBILIDADES DO ENSINO DE QUÍMICA PARA ALUNOS COM DEFICIÊNCIA VISUAL

Grupo C - Duarte (2009). AÇÕES DE EDUCAÇÃO ALIMENTAR E NUTRICIONAL NO ÂMBITO DO PROGRAMA NACIONAL DE ALIMENTAÇÃO ESCOLAR EM MUNICÍPIOS GOIANOS

Fonte: Os autores, 2020.

Em relação às palavras-chave, procuramos realizar uma avaliação sobre sua frequência em todos os trabalhos. Do total de 124 trabalhos, localizamos 487 palavras-chave. Em uma planilha eletrônica, inicialmente procuramos uniformizar a escrita de algumas palavras que estavam no plural ou singular ou que eram sinônimos (Ex: Feiras de Ciências, Feira de Ciências e Feira de Ciência ou Alimentação Escolar e Nutrição Escolar foram todas escritas como Feira de Ciências e Alimentação Escolar, respectivamente). Assim, as 487 palavras foram sintetizadas em 255 sem repetições. Na Figura 5, a frequência das 255 palavras é representada por uma nuvem de palavras. Como se pode notar, há uma diversidade muito grande, pois muitas palavras não se repetem (193 das 255) e apenas 35 foram localizadas em três ou mais trabalhos.

Figura 5 - Nuvem das palavras-chave das 124 produções analisadas.

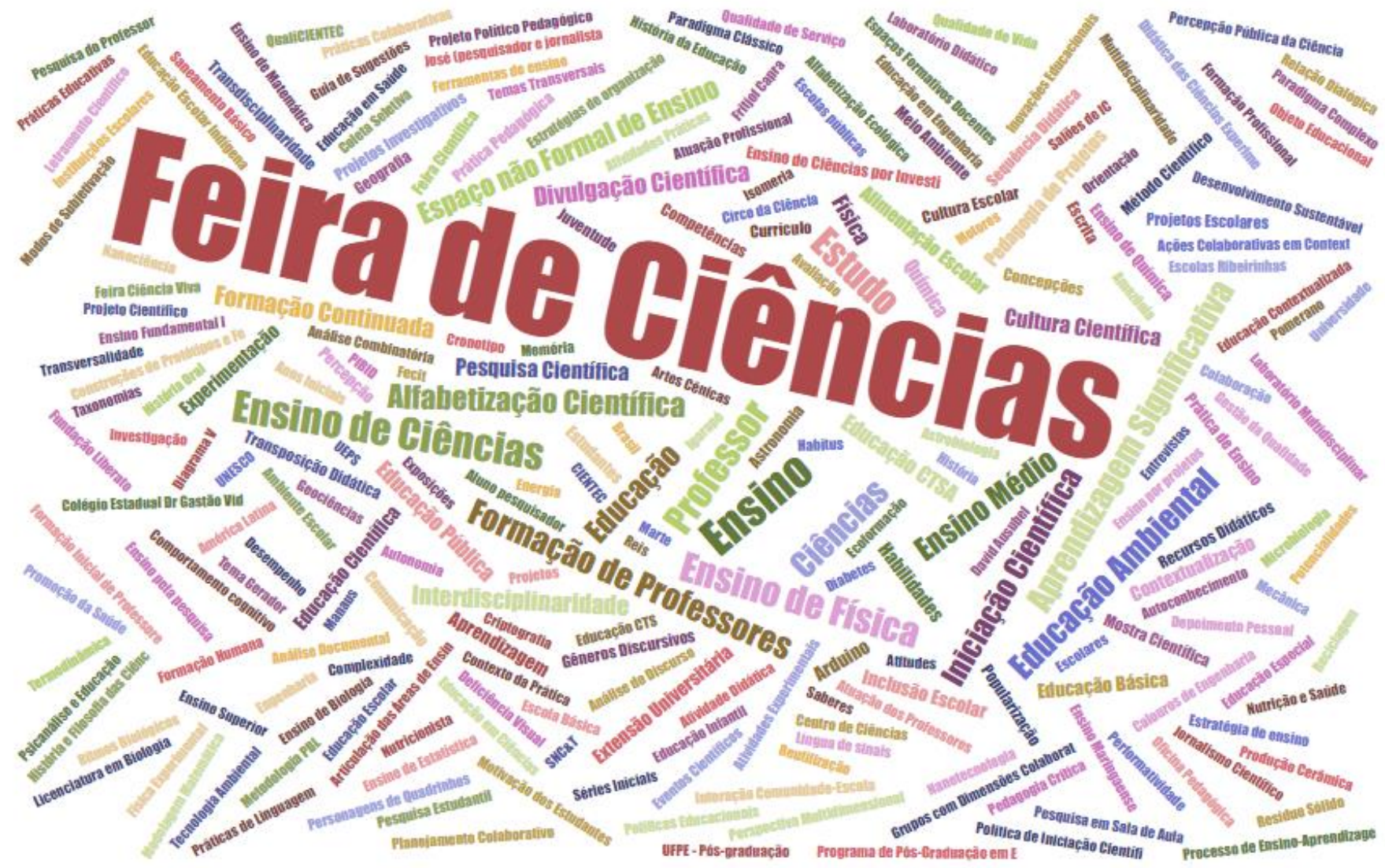

Fonte: Os autores, 2020.

Na nuvem da Figura 6, pode-se observar que 35 palavras que tiveram frequência igual ou superior a três. 
Figura 6 - Nuvem das palavras-chave com frequência igual ou superior a três das 124 produções analisadas.

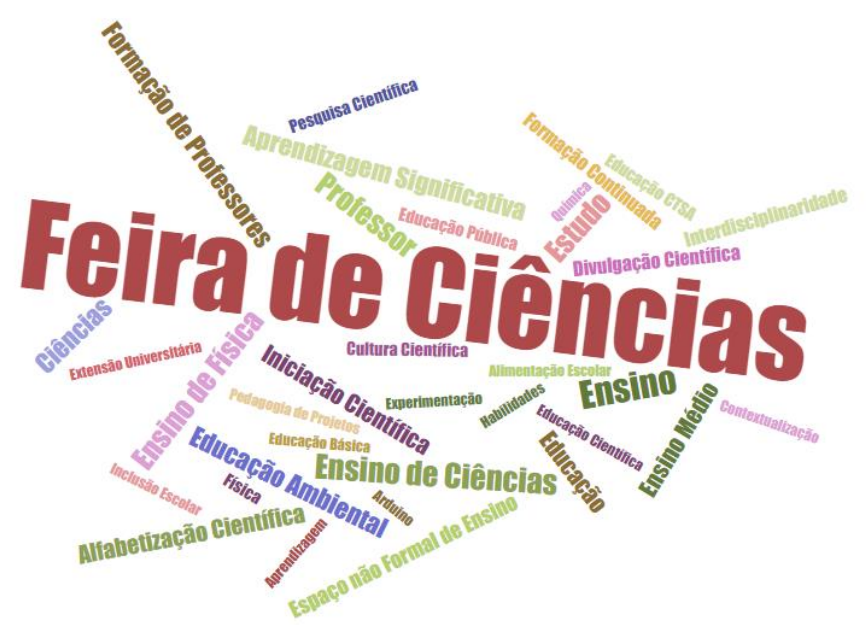

Fonte: Os autores, 2020.

No entanto, apesar de não localizarmos uma uniformidade nas palavras analisadas, encontramos muitas palavras relacionadas com os elementos que julgamos importantes e que estão presentes no nosso mapa de elementos que envolvem uma Feira de Ciências e suas interligações (Figura 1). Das palavras apresentadas na nuvem da Figura 6, destaca-se um grupo com forte relação aos elementos apresentados no mapa da Figura 1. Essas palavras são, por ordem descrente de frequência: Feira de Ciências, Ensino de Ciências, Professor, Formação de Professores, Ciências, Alfabetização Científica, Iniciação Científica, Espaço não Formal de Ensino, Divulgação Científica, Formação Continuada, Interdisciplinaridade, Cultura Científica, Pesquisa Científica, Educação Científica, Experimentação, Contextualização e Pedagogia de Projetos.

Dessa forma, entendemos que o fato de as palavras-chave com maior frequência nas publicações analisadas estarem presentes no mapa construído se torna um indício de que ele é uma representação adequada para o estudo de Feiras de Ciências.

\subsection{Categorias finais}

Com o objetivo de analisar correlações entre as categorias e os grupos estabelecidos, realizamos a separação por grupos e as respectivas categorias dos trabalhos de cada grupo (Figura 7), ou seja, na linha abaixo de cada grupo inserimos colunas com a categoria de cada trabalho (em ordem cronológica) e, para melhorar a ilustração, escolhemos um critério de cores: amarelo para as categorias esperadas (I, II, III), verde para a Categoria IV e azul para a Categoria V.

Figura 7 - Comparação entre categorias e grupos.

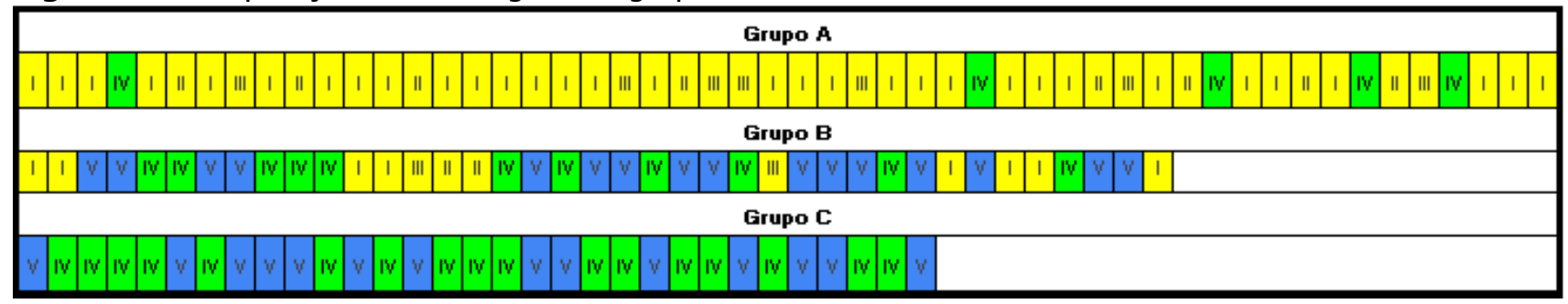

Fonte: Os autores, 2020.

Tal ilustração com cores evidenciou uma boa correlação entre as categorias e os grupos, pois predominou a cor amarela no Grupo A e a azul nos grupos B e C. Assim, com base na Figura 7, podemos inferir que as categorias esperadas (I, II e III) ocorreram predominantemente em trabalhos 
catalogados no Grupo A, apresentando mais um indício de que os trabalhos do Grupo A apresentam explicitamente objetivos das Feiras de Ciências. Por outro lado, os do Grupo C são produções com outros objetivos que propiciaram a apresentação de trabalhos e/ou a realização de Feiras de Ciências ou que envolvem Feiras de Ciências como uma atividade relacionada ao tema pesquisado (categorias IV e V).

Assim, as categorias iniciais e os grupos geraram categorias finais contendo três níveis. A distribuição dos trabalhos pode ser observada na Tabela 1, sobre a qual podemos afirmar que os trabalhos categorizados em A1 são os que apresentam maior abordagem sobre Feiras de Ciências. Tais trabalhos podem ser facilmente identificados na planilha eletrônica (aplicando o recurso de filtro nas Categorias I, II e III e no Grupo A).

Tabela 1 - Categorização final dos trabalhos

\begin{tabular}{|c|c|c|c|c|c|c|}
\hline \multirow{2}{*}{$\begin{array}{c}\text { Categorias } \\
\text { Finais }\end{array}$} & \multicolumn{5}{|c|}{ Categorias Iniciais } & \multicolumn{1}{|c|}{$\begin{array}{c}\text { Total de } \\
\text { Trabalhos } \\
\text { por grupo }\end{array}$} \\
\hline & I & II & III & IV & V & \\
\hline A1 & 32 & 8 & 7 & & & 47 \\
\hline A2 & & & & 5 & & 5 \\
\hline A3 & & & & & 0 & 0 \\
\hline B1 & 8 & 2 & 2 & & & 12 \\
\hline B2 & & & & 11 & & 11 \\
\hline B3 & & & & & 16 & 16 \\
\hline C1 & 0 & 0 & 0 & & & 0 \\
\hline C2 & & & & 17 & & 17 \\
\hline C3 & & & & & 14 & 14 \\
\hline $\begin{array}{c}\text { Total de } \\
\text { Trabalhos } \\
\text { por categoria }\end{array}$ & 40 & 10 & 9 & 33 & 30 & 122 \\
\hline
\end{tabular}

Fonte: Os autores (2020)

Com base na Tabela 1 podemos identificar que dos 122 trabalhos (dois não foram analisados por não estarem disponíveis no formato digital) categorizados houve uma predominância nas categorias esperadas I, II e III (59 trabalhos). Conforme mencionado ao final da seção 4.2, encontramos dificuldades para realizar a categorização entre as categorias I, II e III, mas não encontramos para as demais categorias. Isso nos leva a afirmar que os trabalhos categorizados em I, II e III constituemse em um conjunto de trabalhos que trata substancialmente sobre Feiras de Ciências, uma vez que as categorias IV e $\mathrm{V}$ foram constituídas de forma a posteriori para englobarmos todos as publicações que contém o descritor Feira de Ciências, mas que tiveram outros objetivos de pesquisa.

Em relação aos grupos identificamos uma predominância em A1 (47 trabalhos), ou seja, trabalhos nas categorias e grupo esperado. No entanto, destacamos que se tratando de uma pesquisa em que não foi realizado nenhum recorte temporal, o quantitativo de 47 trabalhos é algo muito pequeno comparado as centenas de dissertações e teses sobre Ensino de Ciências defendidas anualmente.

Para concluir nossa análise, criamos uma codificação para todos os trabalhos encontrados. O código é formado, conforme ilustramos na Figura 8 , pela sigla do estado seguido de um número (que indica 
a ordem cronológica dos trabalhos, em que 1 significa o primeiro trabalho por estado), do tipo de titulação (Mestrado ou Doutorado), da letra do grupo ( $A, B$ ou $C$ ), de um número romano para as categorias (I, II, III, IV ou V) e, por fim, a categorização final. Dessa forma, os trabalhos foram identificados na primeira coluna da planilha eletrônica (Figura 9).

Figura 8 - Código de identificação dos trabalhos

\begin{tabular}{|cccccc|}
\hline Estado & $\begin{array}{c}\text { Ordem } \\
\text { Cronológica }\end{array}$ & Titulação & $\begin{array}{c}\text { Categorias } \\
\text { Iniciais }\end{array}$ & $\begin{array}{c}\text { Grupo } \\
\text { Categorias } \\
\text { Finais }\end{array}$ \\
\hline RS & 1 & MA - Mestrado Acadêmico & I & A & A1 \\
SC & 2 & MP - Mestrado Profissional & II & B & A2 \\
PR & 3 & D - Doutorado & III & C & A3 \\
$\cdots$ & & & IV & & B1 \\
& & & V & & B2 \\
& & & & & B3 \\
& & & & & C1 \\
& & & & C3 \\
\end{tabular}

Fonte: Os autores, 2020.

Figura 9 - Ilustração da tabela construída

\begin{tabular}{|c|c|c|c|c|c|c|c|}
\hline & A & 8 & c & D & E & $F$ & G \\
\hline 1 & IDENTIFICAÇÃO $=$ & ESTADO $=$ & ANO $=$ & TITULAÇÃO $=$ & $\begin{array}{l}\text { CATEGORIAS INICIAIS } \\
\text { CATEGORIZAÇAOO SOBRE } \\
\text { O FOCO DAS PRODUÇÖES }=\end{array}$ & $\begin{array}{c}\text { GRUPOS } \\
\text { CLASSIFICAÇAOO SOBRE } \\
\text { OS OBJETIVOS CONCEITUAIS } \\
\text { DE UMA FEIRA }\end{array}$ & CATEGORIAS FINAIS $=$ \\
\hline 2 & RR3MPVC_C3 & RR & 2018 & Mestrado Profissional & $\mathrm{v}$ & c & $\mathrm{C} 3$ \\
\hline 3 & MA1MPIA_A1 & MA & 2019 & Mestrado Profissional & I & A & A1 \\
\hline 4 & RS12MAlB_B1 & RS & 2018 & Mestrado Acadêmico & II & B & B1 \\
\hline 5 & ES7MPIVC_C2 & ES & 2018 & Mestrado Profissional & IV & c & $\mathrm{C2}$ \\
\hline 6 & MG11MPIA_A1 & MG & 2019 & Mestrado Profissional & I & A & A1 \\
\hline 7 & ES8MPIB_B1 & ES & 2018 & Mestrado Profissional & I & B & B1 \\
\hline 8 & SP19MPIVC_C2 & SP & 2018 & Mestrado Profissional & IV & C & $\mathrm{C2}$ \\
\hline 8 & RS13MPIA_A1 & RS & 2019 & Mestrado Profissional & I & A & A1 \\
\hline 10 & SP2OMAIVA_A2 & SP & 2018 & Mestrado Acadêmico & IV & A & $A_{2}$ \\
\hline 11 & CEEMMAIA_A1 & $\mathrm{CE}$ & 2018 & Mestrado Acadêmico & I & A & A1 \\
\hline 12 & ES9MPIIA_A1 & ES & 2018 & Mestrado Profissional & II & A & A1 \\
\hline 13 & MT4DIA_A1 & MT & 2019 & Doutorado & 1 & A & $\mathrm{A}_{1}$ \\
\hline 14 & RN4MAIIIA_A1 & RN & 2018 & Mestrado Acadêmico & III & A & $\mathrm{A}_{1}$ \\
\hline 15 & RS14MAIA_A1 & RS & 2018 & Mestrado Acadêmico & I & A & A1 \\
\hline 16 & MG12MAIIA_A1 & MG & 2018 & Mestrado Acadêmico & II & A & $\mathrm{A}_{1}$ \\
\hline 17 & CE7MPVC_C3 & CE & 2018 & Mestrado Profissional & v & C & $\mathrm{C3}$ \\
\hline 18 & RS15DVB_B3 & RS & 2018 & Doutorado & v & B & B3 \\
\hline 10 & RS16DIIIA_A1 & RS & 2018 & Doutorado & III & A & A1 \\
\hline 20 & PE5MAVB_B3 & PE & 2019 & Mestrado Acadêmico & $\mathrm{v}$ & B & B3 \\
\hline 21 & MG13MPIVC_C2 & MG & 2019 & Mestrado Profissional & IV & C & $\mathrm{C} 2$ \\
\hline
\end{tabular}

Fonte: Os autores, 2020.

\subsection{Síntese sobre o conceito de Feiras de Ciências}

Retomamos a leitura dos 47 trabalhos selecionados como A1 com o objetivo de complementar a discussão sobre o que caracteriza uma Feira de Ciências e para encontrar mais elementos para propormos uma síntese sobre o conceito. 
De todos os trabalhos analisados, citamos inicialmente Rolan (2016) por destacar que, apesar da retomada crescente das feiras a partir de 2000, os professores que delas participam frequentemente não possuem uma definição clara das características e especificidades de uma Feira de Ciências. Assim, a autora procura conceituar que:

A Feira de Ciências, enquanto processo de ensino, se apoia na educação dialógica, que, segundo Freire (1986), é quando o aluno, ao considerar suas experiências concretas, constrói um diálogo que lhe permite compreender a realidade, em que o conhecimento crítico ou científico supera sua compreensão ingênua de mundo. Promove uma aprendizagem democrática, na qual o diálogo permeia a proposta, desde seu planejamento até sua execução, sendo o aluno sujeito de sua aprendizagem. (ROLAN, 2016, p. 41).

Destaca ainda que partir de um processo de ensino se torna indissociável da culminância em um evento científico, atendendo, portanto, às duas especificidades. Há concordância com a argumentação de Vitor (2016, p. 7), que cita que "Feira de Ciências se torna um ambiente favorável para a Alfabetização Científica, permitindo o desenvolvimento de várias habilidades e competências relacionadas à atividade científica". Enquanto Gewehr $(2019$, p. 7) infere que "projetos de pesquisa e feiras de ciências são espaços de metacognição e autoconhecimento da aprendizagem, oportunizando ganhos cognitivos aos envolvidos".

Diante das citações da segunda seção e dos trabalhos destacados nos parágrafos anteriores, concluímos o presente trabalho sintetizando que Feiras de Ciências são eventos de exposição pública caracterizados como científicos nas escolas ou comunidades, que envolvem apresentações de trabalhos de jovens estudantes desenvolvidos sobre questões do mundo natural, tendo como propósito explorar problemas e soluções de interesse mútuo, promovendo um diálogo que, segundo Rolan $(2016,41)$ "permite compreender a realidade, em que o conhecimento crítico ou científico supera sua compreensão ingênua de mundo". Durante as apresentações, os estudantes oferecem explicações, respondem perguntas e podem contestar críticas sobre os métodos utilizados e conclusões. Assim, espera-se um diálogo com os visitantes e avaliadores sobre os conhecimentos, metodologias de pesquisa e resultados, primando por uma visão contemporânea do conhecimento científico, isto é, que é principalmente uma construção humana, provisória, podendo ser desenvolvido por diversos métodos, passível de contestações e constantemente avaliado pela comunidade científica. Deve-se ter como propósito a superação das simples demonstrações de experimentos, realizadas com o objetivo de "provar" uma teoria. Por último, em relação à avaliação dos trabalhos, os critérios de conhecimentos científicos, originalidade, relação com o contexto dos alunos, pensamento crítico, detalhamento dos métodos, sintetização/interpretação dos resultados e habilidade na apresentação são os mais relevantes.

\section{CONSIDERAÇÕES FINAIS}

Com o objetivo de construir um ambiente virtual para reunir as produções de dissertações e teses sobre Feiras de Ciências, utilizamos uma revisão em três portais e encontramos 124 produções. Ao catalogarmos tais trabalhos, foi identificado que o termo "Feira de Ciências" muitas vezes é usado sem definição consensual. Assim, em etapa anterior às análises, realizamos uma síntese sobre as definições de Feiras de Ciências apresentadas em publicações de autores renomados no tema. Essa síntese propiciou uma construção de 10 objetivos e a elaboração do mapa de elementos que envolvem uma Feira de Ciências e suas interligações (Figura 1). Tal síntese foi complementada na seção anterior com os resultados da presente investigação. Contudo, se tivéssemos que usar poucas 
palavras, apresentaríamos a seguinte definição para Feiras de Ciências: eventos que favorecem o diálogo entre o conhecimento científico e o conhecimento popular para que o conhecimento crítico ou científico auxilie a superar uma compreensão ingênua de mundo e de ciência fragmentada e empirista. Elas também promovem a apresentação e avaliação de investigações inovadoras de alunos da Educação Básica em espaços formais ou não formais de ensino, o que os expõe a novas ideias sobre o mundo natural, os mobiliza para aprender a resolver problemas, aumentam sua consciência social e provocam seu envolvimento em problemas da comunidade (ROLAN, 2016; TERZIAN, 2013).

Tal levantamento demonstrou uma tendência de crescimento, apesar de haver variações em determinados períodos, no número de trabalhos de pós-graduação em stricto sensu ao longo dos anos sobre Feiras de Ciências. Ficou explícito um crescimento sustentável a partir de 2012, que destacamos como indício da relação com o fomento das chamadas anuais do CNPq de apoio a Feiras e Mostras Científicas. Somado a isso, também temos as produções dos mestrados profissionais que se constituíram em 56 trabalhos (quase 50\%) no período de 2012 até 2019.

Em relação ao processo de categorização final, encontramos uma dispersão no foco dos trabalhos, pois muitos, apesar de citarem Feira de Ciências, não a tiveram como tema central de pesquisa. Nessa primeira análise, identificamos que apenas 59 trabalhos tiveram como temática a pesquisa sobre Feiras de Ciências envolvendo eventos, estudantes e professores (conforme as categorias de Gallon et al., 2017). Como perspectiva futura de trabalho, despontam análises mais específicas e profundas sobre determinadas categorias, em especial os 47 trabalhos categorizados em A1, a atualização da planilha com dados de 2020 e a ampliação de artigos publicados em periódicos, eventos e trabalhos de conclusão de cursos de graduação e especializações.

\section{REFERÊNCIAS}

CALDAS, Gracilene Gaia. Atividades experimentais de acústica para o ensino de Física: uma proposta na inclusão de surdos. Dissertação (Mestrado) - Programa de Pós-Graduação em Ensino de Física, Instituto de Ciências Exatas e Naturais, Universidade Federal do Pará, Belém, 2017.

CECIRS (Centro de Treinamento para Professores de Ciências do Rio Grande do Sul). Boletim. Porto Alegre, n.5, p.1-20, 1970.

DEPIERI, Adriana Anunciatto. A engenharia sob a ótica dos pré-universitários e o impacto das feiras de ciências. Tese (Doutorado) - Programa de Pós-Graduação em Ciências, Escola Politécnica de São Paulo, Universidade de São Paulo, São Paulo, 2014.

DUARTE, Renata Zuliani. Professores das séries iniciais do Ensino Fundamental e as feiras de ciências. Dissertação (Mestrado) - Programa de Pós-Graduação em Educação para a Ciência. Faculdade de Ciências, Universidade Estadual Paulista, São Paulo, 2009.

GALLON, Monica Silva; ROCHA FILHO, João Bernardes; NASCIMENTO, Silvania Souza. Feiras de ciências nos ENPECs (1997-2015): identificando tendências e traçando possibilidades. Encontro Nacional de Pesquisa em Educação em Ciências, Florianópolis, 2017. Anais [...] Florianópolis: UFSC, 2017. [online] Disponível em: http://abrapecnet.org.br/enpec/xienpec/anais/resumos/R1722-1.pdf. Acesso em: 23 jul. 2020.

GEWEHR, Diogenes. Projetos de pesquisa e feiras de ciências como espaços de metacognição. Tese (Doutorado) - Programa de Pós-Graduação Stricto Sensu Doutorado em Ensino, Universidade do Vale do Taquari, Lageado, 2019. 
LIMA, Maria Leidiana Oliveira. Feira de ciências: interdisplinaridade no ensino de Biologia para o Ensino Médio. Dissertação (Mestrado Profissional) - Programa de Pós-Graduação em Ensino de Ciências e Matemática da Universidade Federal do Ceará e Matemática Centro de Ciências, Universidade Federal do Ceará, Fortaleza, 2019.

MANCUSO, Ronaldo. Feiras de Ciências no Brasil: uma trajetória de quatro décadas. In: Programa Nacional de Apoio às Feiras de Ciências da Educação Básica: Fenaceb. Brasília: MEC/SEB, 2006. [online] Disponível em: http://portal.mec.gov.br/seb/arquivos/pdf/EnsMed/fenaceb.pdf. Acesso em: 23 de jul. de 2020.

MANCUSO, Ronaldo; LEITE FILHO, Ivo. Feiras de Ciências no Brasil: uma trajetória de quatro décadas. In: Programa Nacional de Apoio às Feiras de Ciências da Educação Básica: Fenaceb. Brasília: MEC/SEB, 2006. [online] Disponível em:

http://portal.mec.gov.br/seb/arquivos/pdf/EnsMed/fenaceb.pdf. Acesso em: 23 de jul. de 2020.

MATOS, Claudete Botaro. Mostra de ciência e tecnologia: instrumento de mudança da visão dos calouros sobre a função da engenharia no mundo moderno. Dissertação (Mestrado Profissional) Programa de Pós-Graduação em Mestrado Profissional em Ensino, Pontifícia Universidade Católica de Minas Gerais, Belo Horizonte, 2014.

MELO, Erika Soares. Ações colaborativas em contexto escolar: desafios e possibilidades do Ensino de Química para alunos co deficiência visual. Dissertação (Mestrado) - Programa de Pós-Graduação em Educação Especial, Universidade Federal de São Carlos, São Carlos: 2013.

MORAES, Roque. Debatendo o ensino de Ciências e as Feiras de Ciências. Boletim Técnico do PROcIRS. Porto Alegre, V. 2, n. 5, p.18-20, 1986.

NASCIMENTO FILHO, Carlos Alberto. Um olhar sobre a $\mathbf{1}^{\mathbf{a}}$ e $\mathbf{2}^{\mathrm{a}}$ feiras de ciências e engenharia do Espírito Santo: a pedagogia de projetos a serviço da educação científica. Dissertação (Mestrado) - Programa de Pós-graduação em Educação em Ciências e Matemática, Instituto Federal do Espírito Santo, Vitória: 2014.

ORMASTRONI, Maria Julieta Sebastiani. Manual de Feira de Ciências. Brasília: CNPq, AED, 1990. 30p.

PEREIRA, Bruna Andrieli Ilha. A presença de indicadores da Alfabetização Científica em trabalhos de Feiras de Ciências. Dissertação (Mestrado) - Programa de Pós-Graduação em Mestrado Profissional em Ensino de Ciências, Universidade Federal do Pampa, Bagé, 2019.

ROCHA, Jéssica Norberto. A cultura científica de professores da Educação Básica: a experiência de formação a distância na Universidade Aberta do Brasil -UFMG. Dissertação (Mestrado) - Programa de Pós-Graduação em Divulgação Científica e Cultural, Universidade Estadual de Campinas, Campinas, 2013.

GODINHO, Janaina Dias. A iniciação à educação científica como ferramenta para a formação do jovem pesquisador: conhecendo as potencialidades procedimentais e atitudinais a serem desenvolvidas nos caminhos investigativos. Dissertação (Mestrado) - Programa de PósGraduação em Ensino de Ciências e Matemática, Universidade Luterana do Brasil, Canoas, 2008.

RODRIGUES, Bárbara Daniela Guedes. A iniciação Científica Júnior Multidisciplinar como Facilitadora da Alfabetização Científica. Dissertação (Mestrado Profissional) - Programa de Pós-Graduação em Mestrado Profissional em Química, Universidade Federal de São Carlos, São Carlos, 2016. 
ROLAN, Catia Viana. Feiras de ciências e mostras científicas: debate e proposta sobre seus conceituais. Dissertação (Mestrado Profissional) - Programa de Pós-Graduação em Ciências e Tecnologias na Educação, Instituto Federal de Educação, Ciência e Tecnologia Sul-Rio-Grandense, Pelotas, 2016.

SANTOS, Keyvilane Fernandes. Feira de ciências no Ensino Médio: atuação dos professores no contexto da prática. Dissertação (Mestrado) - Programa de Pós-Graduação em Ensino, Universidade Federal Rural do Semi-Árido Mossoró, 2019.

SECAB/UNESCO. Convênio "Andrés Bello". Manual para el fomento de las actividades científicas y tecnológicas juveniles. Bogotá: SECAB, 1985.

SILVA, Simoni Urbano da. Ações de educação alimentar e nutricional no âmbito do programa nacional de alimentação escolar em municípios goianos. Dissertação (Mestrado) - Programa de Pós-Graduação em Nutrição e Saúde, Universidade Federal de Goiás, Goiânia, 2013.

SOARES, Leandro Valle. A construção de experimentos pelos alunos do Ensino Técnico Integrado ao Médio: uma proposta de resolução de problemas no contexto de uma mostra escolar de ciência e tecnologia. Dissertação (Mestrado Profissional) - Programa de Pós-Graduação em Mestrado Nacional Profissional em Ensino de Física, Universidade Federal do Espírito Santo, Vitória, 2015.

SOUSA, Maria do Socorro Magalhães. As feiras de ciências em Roraima no período de 1986 a 2008: contribuições para a iniciação à educação científica. Dissertação (Mestrado Profissional) Programa de Pós-Graduação em Ensino de Ciências, Universidade Estadual de Roraima, Boa Vista, 2015.

TERZIAN, Sevan. Science education and citizenship. Estados Unidos, Palgrave Macmillan, 2013.

VITOR, Fernanda Cavalcanti. As feiras de ciências como ambiente para a alfabetização científica. Dissertação (Mestrado Profissional) - Programa de Pós-Graduação Mestrado Profissional em Formação de Professores, Universidade Estadual da Paraíba, Campina Grande UEPB, Campina Grande: 2016.

Submissão: 25/09/2020

Aceito: 09/11/2020 